\title{
In Vivo Metabolism of a Mutant Form of Apolipoprotein A-I, apo A-I Milano, Associated with Familial Hypoalphalipoproteinemia
}

\author{
P. Roma, R. E. Gregg, M. S. Meng, R. Ronan, L. A. Zech, G. Franceschini, * C. R. Sirtori, * and H. B. Brewer, Jr. \\ Molecular Disease Branch, National Heart, Lung and Blood Institute, National Institutes of Health, Bethesda, Maryland 20892; \\ and ${ }^{*}$ Centro E. Grossi Paoletti, Istituto di Scienze Farmacologiche, Milano, Italy
}

\begin{abstract}

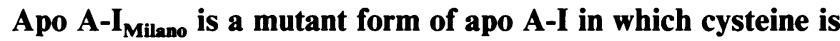
substituted for arginine at amino acid 173. Subjects with apo

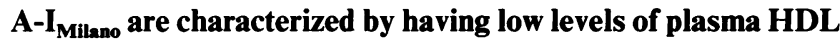
cholesterol and apo A-I. To determine the kinetic etiology of the decreased plasma levels of the apo A-I in these individuals, normal and mutant apo A-I were isolated, radiolabeled with either ${ }^{125} I$ or ${ }^{131} I$, and both types of apo A-I were simultaneously injected into two normal control subjects and two subjects heterozygous for apo A-I $\mathbf{I}_{\text {Milano }}$. In the normal subjects, apo A-I Milano was catabolized more rapidly than the normal apo A-I (mean residence times of $5.11 \mathrm{~d}$ for normal apo A-I vs. $3.91 \mathrm{~d}$ for apo A-I $\mathrm{I}_{\text {Milano }}$ ), clearly establishing that apo A-I $\mathrm{I}_{\text {Milano }}$ is kinetically abnormal and that it has a shortened residence time in

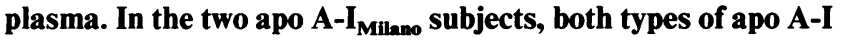
were catabolized more rapidly than normal (residence times ranging from 2.63 to $3.70 \mathrm{~d}$ ) with normal total apo A-I production rates (mean of $10.3 \mathrm{vs} .10 .4 \mathrm{mg} / \mathrm{kg}$ per $\mathrm{d}$ in the normal subjects). Therefore, in the subjects with apo A-I $I_{\text {Milamo, }}$, the decreased apo A-I levels are caused by rapid catabolism of apo A-I and not to a decreased production rate, and the abnormal apo $A-I_{\text {Milano }}$ leads to the rapid catabolism of both the normal and mutant forms of apo A-I in the affected subjects. (J. Clin. Invest. 1993. 91:1445-1452.) Key words: kinetics $\bullet$ lipoproteins - genetic defects - hypoalphalipoproteinemia - apolipoprotein A-I $\bullet$ lipoproteins $\bullet$ HDL
\end{abstract}

\section{Introduction}

HDLs are macromolecular complexes composed of proteins, free and esterified cholesterol, phospholipids, and triglycerides. Apo A-I, the major apolipoprotein of HDL, is synthesized in both the liver and the intestine as a preproprotein (1); this is cotranslationally cleaved to the proprotein, which is secreted into plasma. Within the vascular compartment, proapo A-I is converted to the mature form, a 243-amino acid long polypeptide, by the action of a calcium-dependent protease $(2,3)$. Apo A-I has both a structural and a functional role in lipoprotein metabolism: it is the major structural protein of $\mathrm{HDL}$, it is an activator of the enzyme lecythin:cholesterol acyltransferase

Address correspondence to Dr. Richard E. Gregg at his current address, Bristol Myers Squibb Pharmaceutical Research Institute, Department of Metabolic Diseases, P.O. Box 4000, Princeton, NJ 08543-4000. Dr. P. Roma's present address is Istituto di Scienze Farmacologiche, Milano, Italy.

Received for publication 16 November 1990 and in revised form 19 August 1992.

The Journal of Clinical Investigation, Inc.

Volume 91, April 1993, 1445-1452
$(\operatorname{LCAT})^{1}(4)$ and there is evidence that it has a role as a specific ligand for the HDL receptor (5-7).

HDL cholesterol and apo A-I levels are important negative risk factors for the development of coronary artery disease in humans. Epidemiological and family studies have demonstrated a strong inverse correlation for both HDL cholesterol and apo A-I levels and the incidence of coronary artery disease (8-12), whereas longevity has been reported in individuals with hyperalphalipoproteinemia (13). A mutant form of apo

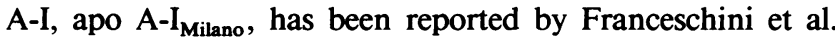
(14), in which a cysteine is substituted for an arginine at amino acid position $173(15)$. All the individuals with this mutation detected so far are heterozygous for the mutant allele (16) and have low to extremely low levels of HDL associated with an increased incidence of hypertriglyceridemia (17). Interestingly, in spite of their hypoalphalipoproteinemia, an increased incidence of cardiovascular disease has not been reported for individuals with apo A-I $\mathrm{I}_{\text {Milano }}(16)$.

Because of the presence of a cysteine residue, apo A-I Milano can form disulfide-linked dimers, and it is present on plasma lipoproteins as a monomer, a heterodimer with apo A-II, and a homodimer with itself (18). In addition, with the loss of the positively charged arginine at position 173 , apo A- $\mathrm{I}_{\text {Milano }}$ has one less net-positive charge than normal apo A-I. This allows visualization of both normal and mutant apo A-I with isoelectric focusing gel electrophoresis of plasma (15). Even though HDL cholesterol and apo A-I levels are low in individuals with apo A-I $\mathrm{I}_{\text {Milano }}$, a high degree of interindividual variability has been observed (19). It is also of interest that the amount of the mutant form of apo A-I is always greater than that of the normal form of the protein, even though the total mass of apo A-I is decreased (14).

Very little is known about the kinetic etiology of the decreased HDL cholesterol and apo A-I levels in subjects with apo A-I $\mathrm{I}_{\text {Milano }}$ and the kinetic mechanism behind the variable ratio of mutant to normal apo A-I in these subjects. We, therefore, performed studies on the in vivo kinetics of both normal apo A-I and apo A-I $\mathrm{I}_{\text {Milano }}$ in normal and apo A-I $\mathrm{I}_{\text {Milano }}$ subjects to investigate the metabolism of the mutant protein and to obtain insights into the mechanism(s) that determine(s) the absolute and relative amounts of the two forms of apo A-I in plasma.

\section{Methods}

Patients and controls. The two study subjects with apo A-I $\mathrm{I}_{\text {Milano }}$ were identified during the screening of asymptomatic family members of the proband for apo A-I $\mathrm{I}_{\text {Miano }}$. Patient 1, a 23-yr-old male, has a history of mild hypertension but has never been treated with medications. Patient

1. Abbreviations used in this paper: LCAT, lecythin:cholesterol acetyltransferase. 
2, a 33-yr-old male, has a history of duodenal ulcer with bleeding, which occurred at the age of 31 . The patient was started on $\mathrm{H} 2$ receptor blockers, and at the time of the study was taking $20 \mathrm{mg}$ famotidine/d. The control subjects, two females, 20 and 21 yr old, were normolipidemic volunteers without evidence of acute or chronic illness. The study protocol was approved by the Investigational Review Board, National Heart, Lung, and Blood Institute, and written informed consent was obtained from each subject. The patients and controls were on an ad libitum diet before admission to the metabolic ward of the Clinical Center at the National Institutes of Health. $1 \mathrm{wk}$ before the beginning of the study, they were put on an isocaloric diet consisting of $16 \%$ protein, $42 \%$ fat, $42 \%$ carbohydrate, $200 \mathrm{mg}$ cholesterol $/ 1,000 \mathrm{kcal}$, and a polyunsaturated to saturated fat ratio of 0.2 . Starting $1 \mathrm{~d}$ before the injection of the tracer and continuing throughout the experiment the subjects were given $300 \mathrm{mg}$ potassium iodide three times per day.

Compositional analysis of plasma lipoproteins. Fasting plasma lipoproteins were isolated by sequential ultracentrifugation at $4^{\circ} \mathrm{C}$ in a 40.3 rotor (Beckman Instruments, Inc., Palo Alto, CA) at the densities of $1.063,1.125\left(\mathrm{HDL}_{2}\right)$, and $1.210 \mathrm{~g} / \mathrm{ml}\left(\mathrm{HDL}_{3}\right)(20)$. Protein content was determined by the method of Lowry et al. (21), using BSA as a standard. Enzymic assays were used for the quantitation of total cholesterol (cholesterol CII, cat. 996-54001; Wako), free cholesterol (free cholesterol C, cat. 274-47109; Wako), triglycerides (triglyceride G, cat. 997-69801; Wako), and phospholipids (phospholipids, cat. 99654001; Wako Bioproducts, Richmond, VA).

Preparation of tracer apolipoproteins and lipoproteins. Normal apo A-I was isolated as previously described (22) and iodinated with ${ }^{131} I$ (NEZ 035H, New England Nuclear/DuPont, Boston, MA) in the presence of $6 \mathrm{M}$ guanidine hydrochloride, $1 \mathrm{M}$ glycine, $\mathrm{pH} 8.5$, as previously reported (3). Less than $0.5 \mathrm{~mol}$ of iodine were covalently bound to $1 \mathrm{~mol}$ of apo A-I. Apo A-I $\mathrm{I}_{\text {Milano }}$ was isolated by affinity chromatography on thiopropyl Sepharose 6B (Pharmacia Fine Chemicals, Piscataway, $\mathrm{NJ}$ ), as previously described (15) and stored as a monomer in a reducing buffer containing $4 \mathrm{M}$ guanidine hydrochloride, $0.1 \mathrm{M}$ Tris $\mathrm{HCl}$, pH 7.4, 0.04\% EDTA, $0.01 \%$ sodium azide, and $20 \mathrm{mM}$ DTT. Before iodination apo A-I $\mathrm{I}_{\text {Milano }}$ was desalted on a Sephadex G-100 column (Pharmacia Fine Chemicals) eluting with $0.01 \mathrm{M} \mathrm{NH}_{4} \mathrm{HCO}_{3}$ buffer, $\mathrm{pH}$ 7.0. The iodination was performed as for normal apo A-I, using ${ }^{125}$ I (NEZ 033L; New England Nuclear/DuPont). After iodination apo A-I $\mathrm{I}_{\text {Milano }}$ was reduced by the addition of DTT in $6 \mathrm{M}$ guanidine hydrochloride, $1 \mathrm{M}$ glycine, $\mathrm{pH} 8.5$, to a final DTT concentration of $50 \mathrm{mM}$. Iodinated apolipoproteins were added at a 1:1,000 dilution ( $\mathrm{vol} / \mathrm{vol}$ ) to fresh plasma (anticoagulated with $1 \mathrm{mg} / \mathrm{ml}$ EDTA) from either a control subject or an apo A-I $\mathrm{I}_{\text {Milano }}$ patient and incubated for 15 $\min$ at $37^{\circ} \mathrm{C}$. Plasma was adjusted to a density of $1.21 \mathrm{~g} / \mathrm{ml}$ with solid $\mathrm{KBr}$, ultracentrifuged at $59,000 \mathrm{rpm}$ for $24 \mathrm{~h}$ at $4^{\circ} \mathrm{C}$ in a $60 \mathrm{Ti}$ rotor with an ultracentrifuge (L8-M; Beckman Instruments Inc.) and the plasma lipoproteins were collected by tube slicing. The labeled lipoproteins were extensively dialyzed against PBS and human serum albumin was added to the lipoproteins at a final concentration of $10 \mathrm{mg} / \mathrm{ml}$. The lipoproteins were sterile filtered and tested for pyrogenicity and sterility (3). Doses of $10 \mu \mathrm{Ci}$ of normal ${ }^{131} \mathrm{I}$-apo A-I and $18-23 \mu \mathrm{Ci}$ of ${ }^{125} \mathrm{I}$-apo A-I $\mathrm{I}_{\text {Milano }}$ were injected into each study subject. The mass of labeled apo A-I injected per subject was $<25 \mu \mathrm{g}$ for each form of apo A-I.

Experimental protocol. Control subjects received labeled normal apo A-I and apo A-I Milano reassociated with control lipoproteins whereas the apo A-I $\mathrm{I}_{\text {Milano }}$ subjects received both forms of labeled apo

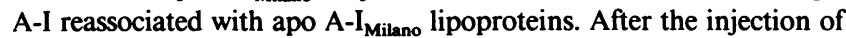
labeled proteins, blood samples were drawn into tubes containing EDTA $(1 \mathrm{mg} / \mathrm{ml})$ and placed immediately on ice. Samples were obtained after the injections at $5 \mathrm{~min}$, at $1,2,3,4,6,9,12,18,24$, and 36 $h$, and on days $2,3,4,5,7,9,11$, and 12 . Plasma was obtained by centrifugation at $1,500 \mathrm{~g}$ for $30 \mathrm{~min}$ at $4^{\circ} \mathrm{C}$. Sodium azide $(0.05 \%)$ and aprotinin ( 200 Kallikrein inhibitor units/ml, Boehringer Mannheim $\mathrm{GmBH}$, Mannheim, Germany) were added to the plasma. Quantitation of radioactivity was obtained by counting 5-ml aliquots of plasma in an Autogamma Counter (model 5260; Packard Instruments Co., Inc., Downers Grove, IL). Total plasma ( $150 \mu \mathrm{l})$ from samples from the first portion of the study ( $5 \mathrm{~min}$ to $36 \mathrm{~h}$ ) were subjected to nonreducing $15 \% \mathrm{NaDodSO}_{4}$ PAGE (23). The gels were stained with Coomassie blue and the apo A-I-containing bands were sliced and counted.

Analysis of kinetic data. Multiexponential functions were fit to the plasma radioactivity decay curves using the SAAM 29 program (24) on a VAX-11/780 computer (Digital Equipment Corp., Maynard, MA). The residence times (RT) were determined from the area under the plasma decay curves. The production rates $(P R)$ were calculated from the following formula:

$$
P R=\frac{\text { apo A-I }(\mathrm{mg} / \mathrm{dl}) \times \text { plasma vol }(\mathrm{dl})}{R T(\mathrm{~d}) \times \text { body wt }(\mathrm{kg})},
$$

with the plasma volume being determined by dividing the total amount of radioactivity injected into each subject by the amount of radioactivity in $1 \mathrm{dl}$ of plasma from the first time point that plasma was obtained $(5 \mathrm{~min})$. The plasma volumes were determined from both tracers injected, and the average of these two determinations were used for all further calculations. In all cases, the differences between the two determinations were $\leq 2 \%$ of the mean value.

Other methods. Cholesterol and triglycerides were determined in plasma using the VP Super System (Abbott Laboratories, Diagnostic Division, Irving, TX). Total HDL cholesterol was quantitated after dextran $\mathrm{SO}_{4}-\mathrm{MgCl}_{2}$ precipitation of apo B-containing lipoproteins in plasma (25). A-I and A-II apolipoproteins were quantitated in total plasma with a radial immunodiffusion assay (26). $\mathrm{NaDodSO}_{4}$ PAGE of plasma and two-dimensional gel electrophoresis of reduced total plasma were performed as described (27).

\section{Results}

The characteristics of the study subjects are reported in Table I. The plasma cholesterol of the patients was in the normal range. HDL cholesterol was below the fifth percentile of age- and sexmatched controls $(21 \mathrm{mg} / \mathrm{dl}$ in patient 1 and $12 \mathrm{mg} / \mathrm{dl}$ in patient 2). Patient 1 had low levels of apo A-I $(86 \mathrm{mg} / \mathrm{dl})$ and

Table I. Characteristics of Patients and Control Subjects

\begin{tabular}{|c|c|c|c|c|c|c|c|c|}
\hline \multirow[b]{2}{*}{ Subject } & \multirow[b]{2}{*}{ Age } & \multirow[b]{2}{*}{ Weight } & \multirow[b]{2}{*}{ Body mass index* } & \multicolumn{5}{|c|}{ Plasma } \\
\hline & & & & Cholesterol & Triglycerides & HDL $^{*}$ & ApoA-I & ApoA-II \\
\hline & $y r$ & $k g$ & $\mathrm{~kg} / \mathrm{m}^{2}$ & \multicolumn{5}{|c|}{$m g / d l$} \\
\hline Patient 1 & 23 & 77 & 22.5 & 199 & 181 & 21 & 86 & 29 \\
\hline Patient 2 & 33 & 77 & 22.4 & 169 & 166 & 12 & 51 & 14 \\
\hline Control 1 & 20 & 48 & 18.2 & 160 & 45 & 43 & 119 & 34 \\
\hline Control 2 & 21 & 64 & 24.2 & 130 & 43 & 47 & 120 & 43 \\
\hline
\end{tabular}

${ }^{*}$ Body mass index $=\mathrm{wt} / \mathrm{ht}^{2} ;{ }^{\ddagger} \mathrm{HDL}$, cholesterol. 
normal levels of apo A-II ( $29 \mathrm{mg} / \mathrm{dl})$. Patient 2 had markedly reduced levels of both apolipoproteins $(51$ and $14 \mathrm{mg} / \mathrm{dl}$ for apo A-I and apo A-II, respectively). The ratios of apo A-I versus apo A-II in the plasma (3.0 and 3.6, respectively) were comparable to those obtained for the control subjects ( 3.6 and 2.8 , respectively). The plasma triglyceride levels were high normal to modestly elevated in both subjects.

Both patients, as all other individuals with apo A-I Milano $_{\text {so }}$ far identified, are heterozygous for the mutant form of apo A-I. Fig. 1 illustrates the results of the two-dimensional gel electrophoresis performed on reduced total plasma. Similar to normal apo A-I, apo A-I Milano has pro, mature, and deamidated isoforms of apo A-I, but with one additional positive charge compared with normal apo A-I. The relative increase in the mass of the mutant apo A-I compared with the normal apo A-I and the interindividual difference in the ratio of the mutant to normal apo A-I in these two patients are consistent with the previously reported relative mass differences and the interindividual variability in the ratio of mutant to normal apo A-I (19).

Composition analysis was performed on lipoproteins isolated at the densities of $1.063-1.125 \mathrm{~g} / \mathrm{ml}\left(\mathrm{HDL}_{2}\right)$ and $1.125-$ $1.210 \mathrm{~g} / \mathrm{ml}\left(\mathrm{HDL}_{3}\right)$. The plasma concentration and the relative percentage of the lipoprotein components are reported in Table II. Both $\mathrm{HDL}_{2}$ and $\mathrm{HDL}_{3}$ in the two patients were relatively enriched in triglycerides and poor in esterified cholesterol. Triglyceride content (6\% in $\mathrm{HDL}_{2}, 4$ and $3 \%$ in $\mathrm{HDL}_{3}$ ) was two to three times higher than in control lipoproteins. Cholesterol esters were 9 and $3 \%$ in $\mathrm{HDL}_{2}$ and 5 and $2 \%$ in $\mathrm{HDL}_{3}$. Control values were 16 and $15 \%$ in $\mathrm{HDL}_{2}, 9$ and $12 \%$ in $\mathrm{HDL}_{3}$. In addition, the free cholesterol to cholesterol ester ratios were elevated for both patients in both HDL subfractions (ranging

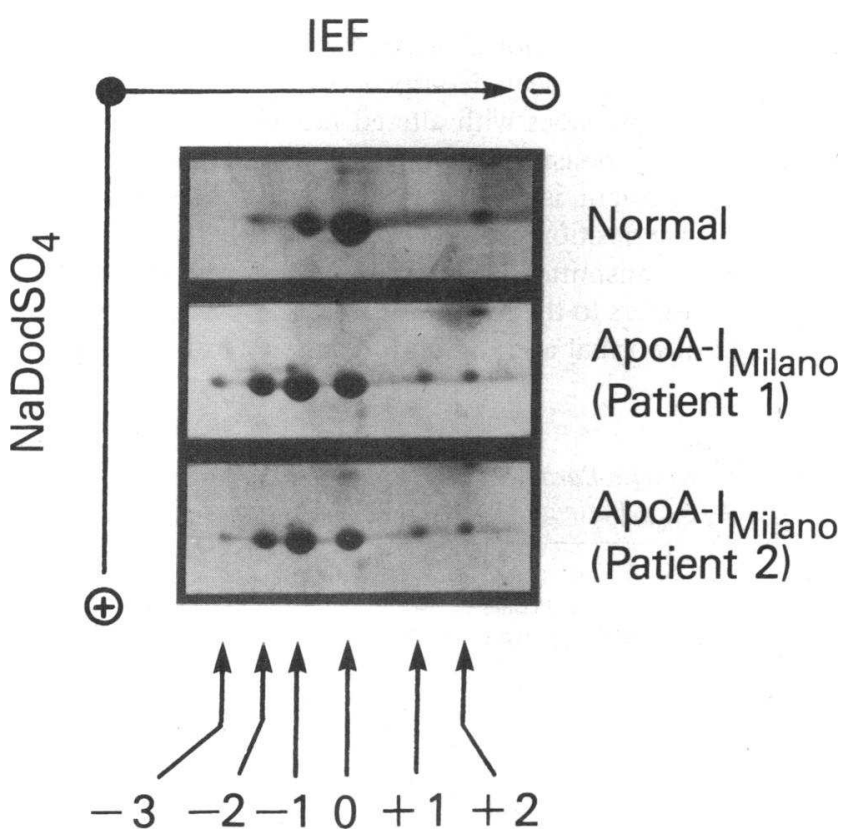

Figure 1. Comparison of the isoforms of normal apo A-I and apo

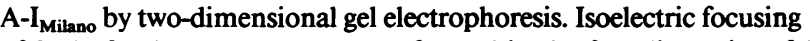
of $3 \mu \mathrm{l}$ of reduced plasma was performed in the first dimension, followed by $\mathrm{NaDodSO}_{4}$ polyacrylamide gel electrophoresis in the second dimension. Proteins were detected by silver stain. Only the portions of the gels containing the apo A-I isoforms are shown. Panels are, from the top, apo A-I from a normal subject and from patients 1 and 2 , respectively. from 0.32 to 1.71 for the patients compared with 0.20 to 0.27 for the controls) with the elevations being greater in patient 2 . When one compared the ratios of free cholesterol with total core components (cholesterol esters plus triglycerides), patient 1 had ratios comparable to the controls ( 0.24 vs. 0.22 and 0.22 for $\mathrm{HDL}_{2}$, and 0.19 vs. 0.22 and 0.18 for $\mathrm{HDL}_{3}$ ) whereas patient 2 still had elevated ratios $\left(0.55\right.$ for $\mathrm{HDL}_{2}$ and 0.50 for $\mathrm{HDL}_{3}$ ). Protein represented a slightly higher than normal percentage of HDL mass. The data in Table II also indicate that the low HDL concentration is mainly due to a decrease in the concentration of $\mathrm{HDL}_{2}$ in patient 1 and to a decrease in the concentration of both HDL subfractions in patient 2 .

After incubation in plasma at $37^{\circ} \mathrm{C}$ and isolation of the lipoprotein fraction at the density of $1.210 \mathrm{~g} / \mathrm{ml}$, the iodinated apo A-I $\mathrm{I}_{\text {Milano }}$ was examined by nonreducing $\mathrm{NaDodSO}_{4}$ gel electrophoresis. A comparison of an autoradiogram of the gel with the Coomassie blue stain (Fig. 2) demonstrated that the iodinated apo A-I $\mathrm{I}_{\text {Milano }}$ was present in three bands, at the molecular weights of 28,000 (apo A-I $\mathrm{I}_{\text {Milano }}$ monomer), 35,000 (apo A$\mathrm{I}_{\text {Milano/apo A-II dimer), and 55,000 (apo A-I }}$ Milano dimer), corresponding to the protein bands for the native apo A- $\mathrm{I}_{\text {Milano }}$ with the stained gels. In addition, the relative intensities of the autoradiogram bands are very similar to the intensities of the stained bands, indicating that the different forms of apo A-I $\mathrm{I}_{\text {Miano }}$ labeled in proportion to their relative mass. Therefore, the kinetic behavior of the radiolabeled apo A-I $\mathrm{I}_{\text {Milano }}$ should reflect the metabolism of its three native circulating forms.

The results of the kinetic studies are illustrated in Figs. 3-5 and in Table III. Fig. 3 depicts the plasma decay curves of apo A-I in one normal control and one apo A-I Milano subject. Apo A-I $\mathrm{I}_{\text {Milano }}$ was catabolized at a faster rate than normal apo A-I with a residence time of 3.9 versus $5.1 \mathrm{~d}$ in the normal control; virtually identical results were obtained from the other normal control with residence times also of 5.1 and $3.9 \mathrm{~d}$ for normal apo A-I and apo A-I Milano, respectively. In the two patients, both apo A-I Milano and normal apo A-I were catabolized at a faster rate than in the normal subjects. The residence time of

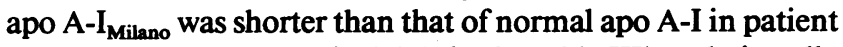
1 ( 3.1 and $3.7 \mathrm{~d}$, respectively) (Fig. 3, Table III) and virtually identical in patient 2 ( 2.6 and $2.7 \mathrm{~d}$, respectively) (Table III). The plasma decay curves of normal apo A-I in a normal control and of apo A-I $\mathrm{I}_{\text {Milano }}$ in the two apo A-I $\mathrm{I}_{\text {Milano }}$ subjects are directly compared in Fig. 4 with patient 2 having the fastest catabolic rate. The apo A-I production rates were normal in both patients ( 10.9 and $9.7 \mathrm{mg} / \mathrm{kg}$ per $\mathrm{d}$ for patients 1 and 2 , respectively; Table III).

A further insight into the metabolism of apo A- $\mathrm{I}_{\text {Milano }}$ was obtained by following the radioactivity associated with its monomer and dimer bands after nonreducing $\mathrm{NaDodSO}_{4}$ gel electrophoresis of total plasma (Fig. 5). Apo A-I ${ }_{\text {Milano }}$ was catabolized much more rapidly as a monomer than as a dimer: $50 \%$ of the activity initially present in the monomeric form was metabolized within the first $6 \mathrm{~h}$; at $36 \mathrm{~h}$ counts had further decreased to $30 \%$ in the normal control and to $20 \%$ in the patient. Conversely, after an initial raise, $80 \%$ of the activity associated with the dimers was still present in the plasma of the control subject at $36 \mathrm{~h}$; at the same time $50 \%$ of the initial dimer activity was found in the plasma isolated from the patient (Fig. 5).

The amount of labeled apo A-I that was lipoprotein free (i.e. in the $1.21 \mathrm{~g} / \mathrm{ml}$ bottom fraction) after ultracentrifugation was determined at the $1-\mathrm{h}$ time point with the following results: 
Table II. Mass and Percent Composition of $\mathrm{HDL}_{2}$ and $\mathrm{HDL}_{3}$

\begin{tabular}{|c|c|c|c|c|c|}
\hline & \multicolumn{5}{|c|}{$\mathrm{HDL}_{2}$} \\
\hline & Protein & $\mathrm{CE}$ & FC & TG & PL \\
\hline & \multicolumn{5}{|c|}{$m g / d l(\%)$} \\
\hline Patient 1 & $0.379(56)^{*}$ & $0.062(9)$ & $0.024(4)$ & $0.039(6)$ & $0.176(26)$ \\
\hline Patient 2 & $0.164(61)$ & $0.007(3)$ & $0.012(4)$ & $0.015(6)$ & $0.071(27)$ \\
\hline Control 1 & $0.649(51)$ & $0.201(16)$ & $0.053(4)$ & $0.040(3)$ & $0.342(27)$ \\
\hline \multirow[t]{2}{*}{ Control 2} & $0.718(56)$ & $0.198(15)$ & $0.048(4)$ & $0.022(2)$ & $0.306(24)$ \\
\hline & \multicolumn{5}{|c|}{$\mathrm{HDL}_{3}$} \\
\hline Patient 1 & $0.552(72)$ & $0.041(5)$ & $0.013(2)$ & $0.027(4)$ & $0.134(17)$ \\
\hline Patient 2 & $0.386(77)$ & 0.009 (2) & $0.013(3)$ & $0.017(3)$ & $0.079(16)$ \\
\hline Control 1 & $0.610(70)$ & $0.074(9)$ & $0.020(2)$ & $0.016(2)$ & $0.150(17)$ \\
\hline Control 2 & $0.622(65)$ & $0.117(12)$ & $0.023(2)$ & $0.012(1)$ & 0.178 (19) \\
\hline
\end{tabular}

CE, cholesterol esters; FC, free cholesterol; TG, triglycerides; PL, phospholipids. * The numbers in parentheses are the percent composition of that component in that density range.

for patient 1 , apo A-I $\mathrm{I}_{\text {Milano }}$ in the $1.21 \mathrm{~g} / \mathrm{ml}$ bottom fraction, $10.1 \%$; normal apo A-I, $10.7 \%$; for patient 2 , apo A-I $\mathrm{I}_{\text {Milano }}$ 13.4\%; normal apo A-I, 20.7\%; for control 1, apo A-I $\mathrm{I}_{\text {Milano }}$ 9.8\%; normal apo A-I, $6.8 \%$; for control 2, apo A-I for normal apo A-I, 6.1\%. The percentage of free normal apo

A Coomassie Blue Stain
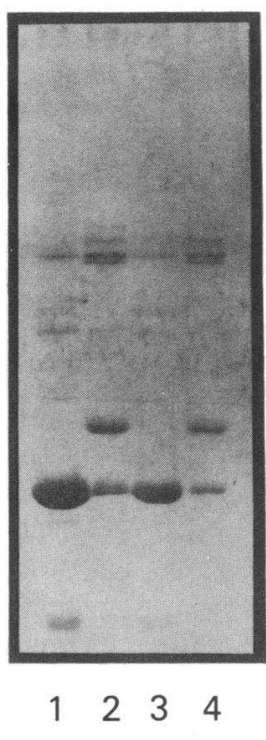

$\mathrm{N} P t \mathrm{~N}$ t
B Autoradiogram
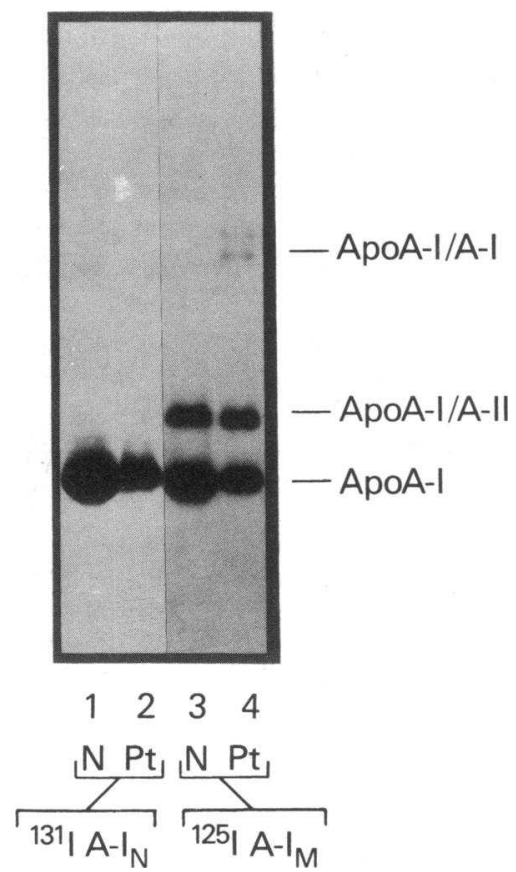

Figure 2. Coomassie blue stain $(A)$ and autoradiogram $(B)$ of a $12 \%$ nonreducing $\mathrm{NaDodSO}_{4}$ gel of the $1.21 \mathrm{~g} / \mathrm{ml}$ density top fraction isolated after incubation for $15 \mathrm{~min}$ at $37^{\circ} \mathrm{C}$ of lane $1,{ }^{131} \mathrm{I}$ normal apo A-I with normal plasma; lane $2,{ }^{131}$ I normal apo A-I with A-I $\mathrm{I}_{\text {Miano }}$ plasma; lane 3, ${ }^{125} \mathrm{I}$ apo A-I $\mathrm{I}_{\text {Milano }}$ with normal plasma; and lane 4, ${ }^{125} \mathrm{I}$ apo A-I $\mathrm{I}_{\text {Milano }}$ with A-I $\mathrm{I}_{\text {Milano }}$ plasma.
A-I at each time point remained relatively constant throughout the course of the study for all four subjects. The percentage of free apo A-I $\mathrm{I}_{\text {Milano }}$ at each time point decreased by $\sim 35-40 \%$ by $12 \mathrm{~h}$ in both patients and controls and then remained relatively constant for the rest of the study.

\section{Discussion}

Several variant forms of apolipoproteins that are caused by point mutations, deletions, or rearrangements in the corresponding genes have been described. A number of these mutations result in peptides with altered functions and abnormal lipoprotein metabolism. Apo A-I $\mathrm{I}_{\text {Milano }}$, the first described mutant apolipoprotein, is characterized by a cysteine for arginine substitution at position 173 in the amino acid sequence and the mutation is transmitted as an autosomal dominant trait. The mutation confers to the protein a more acidic isoelectric point than that of normal apo A-I and the ability to form disulfide

Table III. Kinetic Parameters of Apo A-I Metabolism

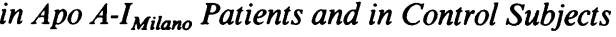

\begin{tabular}{|c|c|c|c|c|c|}
\hline \multirow[b]{2}{*}{ Subject } & \multirow[b]{2}{*}{ Apo A-I } & \multirow{2}{*}{$\begin{array}{l}\text { Plasma } \\
\text { volume }\end{array}$} & \multicolumn{2}{|c|}{ Apo A-I residence time } & \multirow{2}{*}{$\begin{array}{l}\text { Production } \\
\text { rate }\end{array}$} \\
\hline & & & Normal & Mutant & \\
\hline & $m g / d l$ & $d l$ & \multicolumn{2}{|c|}{$d$} & $\mathrm{mg} / \mathrm{kg}$ per \\
\hline Patient 1 & 86 & 33.1 & $3.70 \pm 0.06^{*}$ & $3.13 \pm 0.05$ & 10.9 \\
\hline Patient 2 & 51 & 38.7 & $2.65 \pm 0.02$ & $2.63 \pm 0.02$ & 9.7 \\
\hline Control 1 & 119 & 22.5 & $5.09 \pm 0.06$ & $3.94 \pm 0.23$ & 11.0 \\
\hline Control 2 & 120 & 26.6 & $5.12 \pm 0.31$ & $3.88 \pm 0.37$ & 9.7 \\
\hline $\begin{array}{l}\text { Historic } \\
\text { Controls } \\
\quad(n=7)\end{array}$ & $126 \pm 17$ & & $4.91 \pm 0.43$ & - & $10.3 \pm 1.2$ \\
\hline
\end{tabular}

$* \pm \mathrm{SD}$ 

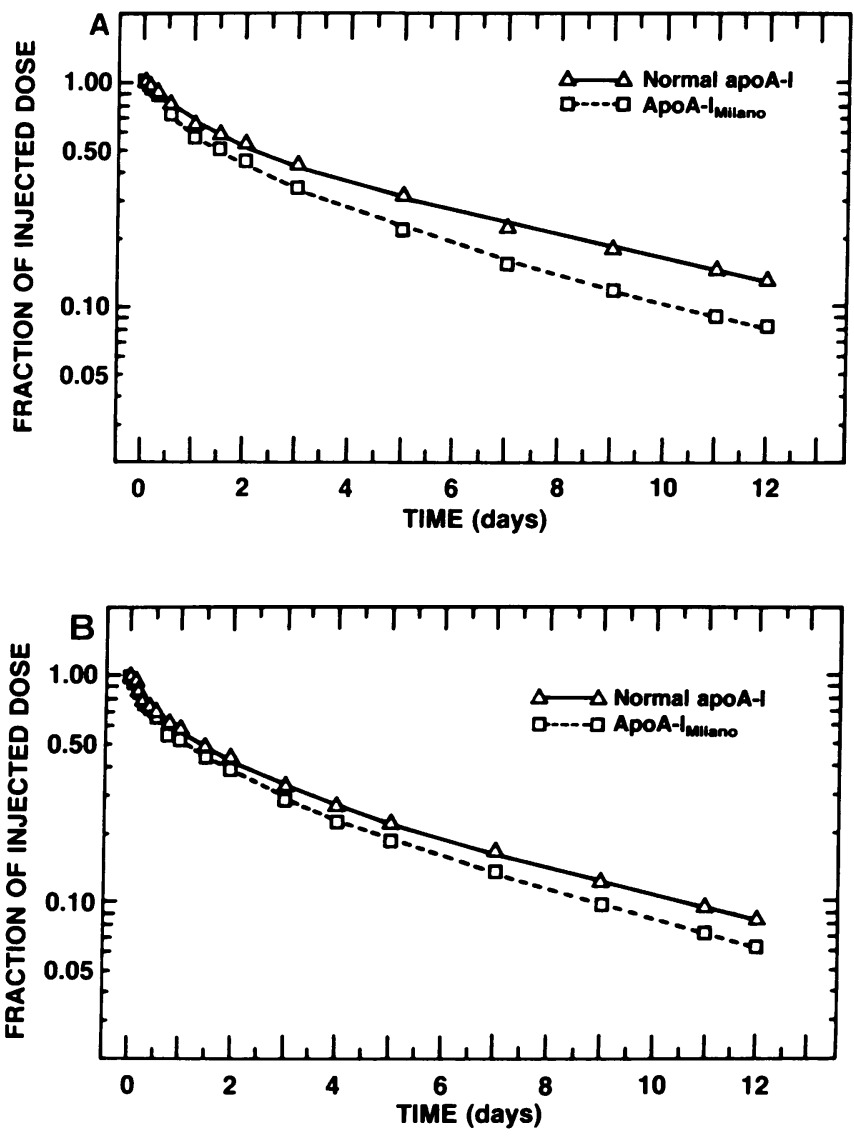

Figure 3. (A) Plasma radioactivity decay curves of normal apo A-I $(\triangle)$ and apo A-I $\mathrm{I}_{\text {Milano }}(\square)$ in a normal subject. (B) Plasma radioactivity decay curves of normal apo A-I $(\triangle)$ and apo A-I Milano $(\square)$ in an apo A-I Milano $_{\text {subject. }}$

bonds, principally as homodimers and as heterodimers with apo A-II. Since the description of the first case $(14,15)$, a number of additional affected individuals have been found as a result of screening in the geographic area from which the proband originated. Although to various degrees, the plasma lipoprotein profile is altered in all of these individuals. Apo

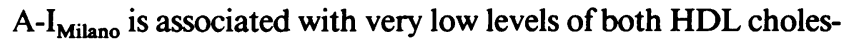
terol and apo A-I with an increased incidence of hypertriglyceridemia (17), which in the index case was resistent to drug therapy (14). In spite of the altered plasma lipid and lipoprotein profile, no increased incidence of clinical manifestations of atherosclerotic vascular disease was observed among apo A-I $\mathrm{I}_{\text {Milano }}$ subjects $(17,19)$. In vitro studies on the interaction of apo A-I Milano $_{\text {with lipids (28) and with HDL particles isolated from }}$ plasma of apo A-I $\mathrm{I}_{\text {Milano }}$ subjects (29-32) have been performed. The arginine to cysteine substitution in apo A-I $\mathrm{I}_{\text {Milano }}$ results in an accelerated rate of association of apo A-I $\mathrm{I}_{\text {Milano }}$ with lipids and reduced stability of the lipid-apolipoprotein complexes (28). Preferential distribution of apo $\mathrm{A}-\mathrm{I}_{\text {Milano }}$ monomers and dimers with $\mathrm{HDL}_{3}$ was also observed in HDL particles separated by gel filtration chromatography (29). In addition, the occurrence of apo A-I $\mathrm{I}_{\text {Milano }}$ dimers did not significantly affect the relative distribution of HDL particles with and without apo A-II isolated by immunoaffinity chromatography ( 30 ) but did affect the in vitro metabolic activity of these particles (31).
Also of interest, individuals with apo A-I $\mathrm{I}_{\text {Milano }}$ have been demonstrated to have reduced levels of LCAT protein and LCAT activity (32).

The two apo A-I $\mathrm{I}_{\text {Milano }}$ patients taking part in this study were healthy young males with the characteristics of previously reported subjects. They were modestly hypertriglyceridemic, had normal levels of plasma cholesterol, and significantly decreased levels of HDL cholesterol. Their plasma apo A-I levels were decreased, although not to as great an extent as their HDL cholesterol levels would predict. Studies on plasma lipoproteins demonstrated an abnormal composition of both HDL subclasses, with triglycerides being proportionally increased and cholesterol esters decreased. The change in composition was particularly evident in patient 2 , who had the lower HDL level. In addition, on an absolute mass basis, $\mathrm{HDL}_{2}$ levels were more decreased than $\mathrm{HDL}_{3}$ in these two subjects, a common finding among individuals with hypoalphalipoproteinemia caused by a number of different etiologies.

The decrease in cholesterol esters in HDL, and particularly the increase in the free cholesterol to cholesterol esters and the free cholesterol to cholesterol esters plus triglycerides ratios in patient 2 , is consistent with the previously described decrease in LCAT activity in subjects with apo A-I $\mathrm{I}_{\text {Milano }}$ (32). The reasons for the substantial differences in lipoprotein composition and apo A-I kinetics between these two subjects is unknown, but these types of differences have been previously described $(19,29,32)$. It is interesting to speculate that there may be a second genetic defect in some apo $\mathrm{A}-\mathrm{I}_{\text {Milano }}$ individuals, such as a partial LCAT deficiency or a primary over production of triglycerides, resulting in these compositional and metabolic differences; although other factors such as diet or level of physical activity or the hormonal status of women may secondarily result in these differences. The current study does not and was not designed to provide any direct evidence to support any of these hypotheses.

Apo A-I $\mathrm{I}_{\text {Milano }}$ is present in native plasma principally in three forms, as a monomer, a homodimer, and a heterodimer. To determine the kinetics of their metabolism, it was important to have all three forms labeled with the radioactive tracer. Our results with $\mathrm{NaDodSO}_{4}$ PAGE of the labeled apo A-I $\mathrm{I}_{\text {Milano, }}$, which was added to plasma in a reduced state after iodination, indicated that during the incubation with plasma at $37^{\circ} \mathrm{C}$ the

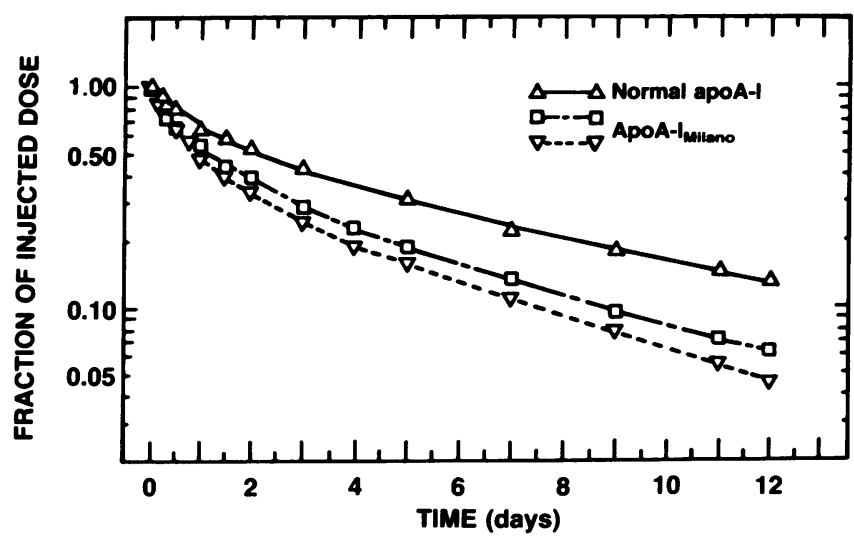

Figure 4. Plasma radioactivity decay curves of normal apo A-I in a normal subject $(\Delta)$ and of apo A-I $\mathrm{I}_{\text {Milano }}$ in the two apo A-I $\mathrm{I}_{\text {Milano }}$ subjects $(\square, \nabla)$. 

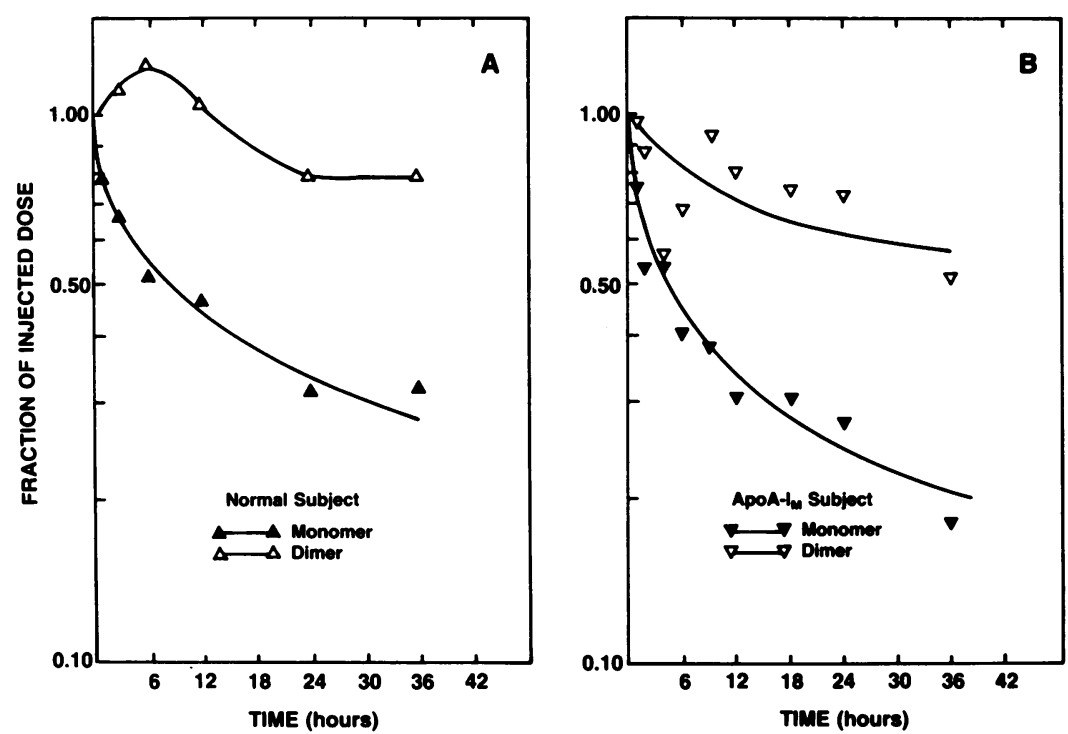

Figure 5. Plasma radioactivity decay curves of apo A-I monomer $(\Delta, \nabla)$ and dimers $(\Delta, \nabla)$ in normal subject $1(A)$ and in apo A-I $\mathrm{I}_{\text {Milano }}$ subject $2(B)$, as determined from $\mathrm{NaDodSO}_{4}$ gel electrophoresis of nonreduced total plasma. Counts at each time point are expressed as a percentage of radioactivity of the respective bands at $5 \mathrm{~min}$ after the injection of labeled apo A-I $\mathrm{I}_{\text {Milano }}$. protein was able to form homodimers and heterodimers with apo A-II in approximately the same proportion as they exist in native plasma. Thus, we were able to appropriately radiolabel all three forms of apo A-I $\mathrm{I}_{\text {Milano }}$ for the kinetic study.

The results obtained from this study clearly indicate that apo A-I $\mathrm{I}_{\text {Milano }}$ is metabolically abnormal; this is most directly demonstrated by the significantly more rapid catabolism of apo A-I $\mathrm{I}_{\text {Milano }}$ compared with normal apo A-I in the normal control subjects. The kinetics of metabolism of apo A-I were more complex in the two subjects with apo A-I $\mathrm{I}_{\text {Milano }}$ in that both normal apo A-I and apo A-I $\mathrm{I}_{\text {Milano }}$ were catabolized more rapidly than either type of apo A-I in normal subjects. Since there are two to four molecules of apo A-I per HDL particle, when tracer amounts of apo A-I $\mathrm{I}_{\text {Milano }}$ are injected in normal subjects, there will be only one mutant apo A-I per particle, whereas virtually all of the normal apo A-I will be on particles containing only normal apo A-I. Therefore, one will be determining the metabolism of normal apo A-I on a normal particle or the metabolism of apo A-I $\mathrm{I}_{\text {Milano }}$ on a particle that contains only one copy of the abnormal apo A-I. In the apo A-I Milano subjects, both the normal and mutant radiolabeled forms of apo A-I will be on particles that contain unlabeled forms of both normal apo A-I and apo A-I $\mathrm{I}_{\text {Milano }}$. Our studies suggest that at least some HDL particles in the apo A-I Milano $_{\text {subjects are }}$ catabolized as a whole and that the presence of a rapidly catabo-
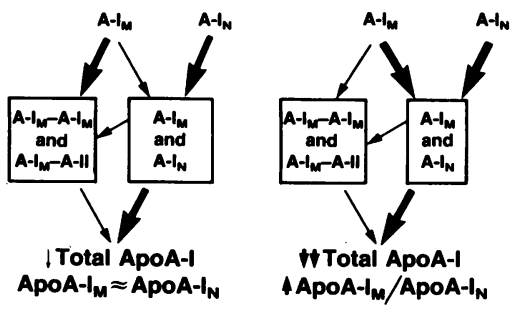

Figure 6. Schematic representation of the metabolism of apo A-I in apo A-I $\mathrm{I}_{\text {Milano }}$ subjects. Left, the situation in which plasma levels of HDL cholesterol and apo A-I are modestly decreased and the concentration of mutant and normal apo A-I are similar. Right, the situation in which plasma levels of HDL cholesterol and apo A-I are markedly decreased and the ratio of mutant vs. normal apo A-I is relatively increased. See text for further details. lized, unlabeled, abnormal apo A-I $\mathrm{I}_{\text {Milano }}$ in the affected patients resulted in the rapid catabolism of both radiolabeled normal and mutant apo A-I.

When the catabolic rates of the monomer and dimer forms of apo A-I $\mathrm{I}_{\text {Milano }}$ were evaluated, it was found that the monomer form, in addition to being catabolized more rapidly than normal apo A-I, was catabolized much more rapidly than the

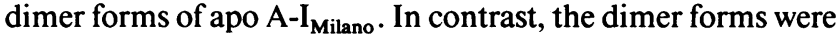
catabolized somewhat more slowly than normal apo A-I in these subjects. These findings are important in the understanding of the kinetics of apo A-I metabolism that lead to rapid catabolism of both normal and mutant apo A-I. In addition, they can also explain the paradoxical findings that in subjects with apo A-I $\mathrm{I}_{\text {Milano, }}$, even though the mutant apo A-I is catabolized more rapidly than apo A-I in a normal subject, the apo A-I $\mathrm{I}_{\text {Milano }}$ is present in plasma at a higher concentration than is the normal form of apo A-I and that the subjects with the lowest levels of apo A-I and HDL cholesterol have the highest amounts of apo A-I $\mathrm{I}_{\text {Milano }}$ relative to normal apo A-I.

The results of the determination of the amount of free apo A-I in the study are consistent with previous findings that apo A-I $\mathrm{I}_{\text {Milano }}$ destabilizes lipid-apolipoprotein complexes (28) in that both of the study subjects had a larger percentage of both forms of free apo A-I in plasma. In addition, the relative decrease in the percentage of free apo A- $\mathrm{I}_{\text {Milano }}$ over time parallels the rapid catabolism of apo A- $\mathrm{I}_{\text {Milano }}$ monomer, suggesting that the dimer binds more tightly to lipoprotein particles than does the monomer. One can not determine from this study if the

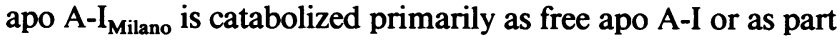
of a particle. Apo A-I $\mathrm{I}_{\text {Milano }}$ may be recognized by a cell surface receptor that leads to internalization and degradation of the whole particle. This is consistent with the rapid catabolism of both normal and mutant apo A-I in the apo A-I $\mathrm{I}_{\text {Milano }}$ patients. In addition, the site of uptake would be more likely to be in the liver in that these subjects do not have xanthomas or accelerated atherosclerosis, which would be more consistent with a peripheral uptake of whole HDL particles. However, there is evidence that apo A-I $\mathrm{I}_{\text {Milano }}$ destabilizes the whole HDL particle, resulting in increased amounts of both normal and mutant free apo A-I, and one can not rule out that this results in the rapid 
catabolism of both normal and mutant apo A-I. The authors currently favor the first hypothesis for rapid catabolism of apo A-I in apo A-I $\mathrm{I}_{\text {Milano }}$ subjects, although there is no convincing evidence favoring one mechanism over the other.

Our proposed model for the metabolism of apo A-I in subjects with apo A-I $\mathrm{I}_{\text {Milano }}$ is schematically depicted in Fig. 6. The left panel depicts the situation in apo A-I $\mathrm{I}_{\text {Milano }}$ subjects with modest decreases in plasma apo A-I and HDL cholesterol levels, similar to patient 1 , whereas the right panel represents the metabolism of apo A-I in apo A-I $\mathrm{I}_{\text {Milano }}$ subjects with more marked decreases in plasma apo A-I and HDL, similar to patient 2 . After synthesis, apo A-I $\mathrm{I}_{\text {Milano }}$ can enter two metabolically different pools, the rapidly catabolized monomer pool or the slowly catabolized dimer pool. If the newly formed apo A-I preferentially enters the dimer pool, the majority of apo A-I $\mathrm{I}_{\text {Milano }}$ will be catabolized somewhat more slowly than normal apo A-I. Since monomeric apo A- $\mathrm{I}_{\text {Milano }}$ is a minor proportion of the total plasma apo A-I, only a minor amount of mutant and normal apo A-I will be rapidly catabolized, resulting in a modest decrease in the plasma levels of mutant and normal apo A-I and of HDL cholesterol. In addition, since apo A- $\mathrm{I}_{\text {Milano }}$ dimers are catabolized only slightly slower than normal apo A-I, there will not be a substantial decrease of normal apo A-I relative to apo A-I $\mathrm{I}_{\text {Milano }}$.

In contrast, if the newly formed apo A-I $\mathrm{I}_{\text {Milano }}$ preferentially enters the monomer pool, a larger amount of the mutant apo A-I will be rapidly catabolized. This will also result in a much greater amount of normal apo A-I being rapidly catabolized, with a substantial depletion of both normal and mutant forms of apo A-I from plasma. On the other hand, the apo A- $\mathrm{I}_{\text {Milano }}$ dimers will not be as rapidly catabolized, and although decreased in concentration compared with those in the left-hand panel, they will be increased in concentration relative to normal apo A-I. The end result of this is a marked decrease in plasma apo A-I and HDL cholesterol levels with normal apo A-I being decreased more than apo A-I $\mathrm{I}_{\text {Milano }}$.

These investigations in subjects with apo A-I $\mathrm{I}_{\text {Milano }}$ have resulted in important information on the regulation of the metabolism of apo A-I in this disease and have led to the first insights into the metabolic etiology of the paradoxical relative increase in the levels of mutant apo A-I compared with normal apo A-I. It remains for future investigations to determine where the dimerization of apo A- $\mathrm{I}_{\text {Milano }}$ occurs and what determines the relative proportion of the mutant apo A-I that goes into the dimer versus the monomer pool. Thus apo A-I $\mathrm{I}_{\text {Milano, }}$, the first mutant apolipoprotein discovered, continues to provide important insights into the function and metabolic control of apo A-I in humans.

\section{Acknowledgments}

We thank the nursing staff on ward 8 East and the metabolic kitchen staff of the National Institutes of Health Clinical Center for caring for the study subjects; and Ms. Diana Hernandez, Barbara Winterrowd, and Tracy Wahl for excellent technical assistance. We also thank Ms. Joanie Gault for typing the manuscript. Most of all, we would like to express our appreciation to the normal volunteers and the patients for making this study possible.

This work was supported in part by the Consiglio Nazionale delle Richerche of Italy (PF Ingegneria Genetica).

\section{References}

1. Law, S. W., and H. B. Brewer, Jr. 1984. Nucleotide sequence and the encoded amino acids of human apolipoprotein A-I mRNA. Proc. Natl. Acad. Sci. USA. 81:66-70.

2. Edelstein, C., J. I. Gordon, K. Toscas, H. Sims, A. W. Strauss, and A. M. Scanu. 1983. In vitro conversion of proapolipoprotein A-I to apoprotein A-I: partial characterization of an extracellular enzyme activity. J. Biol. Chem. 258:11430-11433.

3. Bojanovski, D., R. E. Gregg, G. Ghiselli, E. J. Schaefer, J. A. Light, and H. B. Brewer, Jr. 1985. Human apolipoprotein A-I isoprotein metabolism: proapoA-I conversion to mature apo A-I. J. Lipid Res. 26:185-193.

4. Fielding, C. J., V. G. Shore, and P. E. Fielding. 1972. A protein cofactor of lecithin:cholesterol acyltransferase. Biochem. Biophys. Res. Commun. 46:14931498.

5. Biesbroeck, R., J. F. Oram, J. J. Albers, and E. L. Bierman. 1983. Specific high-affinity binding of high density lipoproteins to cultured human skin fibroblasts and arterial smooth muscle cells. J. Clin. Invest. 71:525-539.

6. Fidge, N. H., and P. J. Nestel. 1985. Identification of apolipoproteins involved in the interaction of human high density lipoprotein 3 with receptors on cultured cells. J. Biol. Chem. 260:3570-3575.

7. Graham, D. L., and J. F. Oram. 1987. Identification and characterization of a high density lipoprotein binding protein in cell membranes by ligand blotting. J. Biol. Chem. 262:7439-7442.

8. Gordon, T., W. P. Castelli, M. C. Hjortland, W. B. Kannel, and T. R. Dawber. 1977. High density lipoprotein as a protective factor against coronary heart disease. The Framingham Study. Am. J. Med. 62:707-714.

9. Maciekjo, J. J., D. R. Holmes, B. A. Kottke, A. R. Zimsmaister, D. M. Dihn, and S. J. T. Mao. 1983. Apolipoprotein A-I as a marker for angiographically assessed coronary artery disease. N. Engl. J. Med. 309:385-389.

10. De Backer, G., M. Rosseneu, and J. P. Deslypere. 1982. Discriminative values of lipids and apoproteins in coronary heart disease. Atherosclerosis. 42:197-203.

11. Vergani, C., and G. Bettale. 1981. Familial hypoalphalipoproteinemia. Clin. Chim. Acta. 114:45-52.

12. Third, J. L., J. Montag, M. Flynn, J. Freidel, P. Laskarzewski, and C. J. Glueck. 1984. Primary and familial hypoalphalipoproteinemia. Metabolism. 33:136-146.

13. Glueck, C. J., P. Gartside, R. W. Fallat, J. Sielski, and P. M. Steiner. 1976. Longevity syndromes: familial hypobeta and familial hyperalpha lipoproteinemia. J. Lab. Clin. Med. 88:940-957.

14. Franceschini, G., C. R. Sirtori, A. Capurso, K. H. Weisgraber, and R. W. Mahley. 1980. A-I $\mathrm{I}_{\text {Milano }}$ apoprotein. Decreased high density lipoprotein cholesterol levels with significant lipoprotein modifications and without clinical atherosclerosis in an Italian family. J. Clin. Invest. 66:892-900.

15. Weisgraber, K. H., S. C. Rall, T. P. Bersot, R. W. Mahley, G. Franceschini,

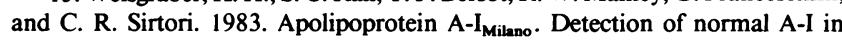
affected subjects and evidence for a cysteine for arginine substitution in the variant A-I. J. Biol. Chem. 258:2508-2513.

16. Gualandri, V., G. Franceschini, C. R. Sirtori, G. Gianfranceschi, G. B. Orsini, A. Cerrone, and A. Menolli. 1985. A-I Milano apoprotein. Identification of the complete kindred and evidence of a dominant genetic transmission. Am.J. Hum. Genet. 37:1083-1097.

17. Franceschini, G., C. R. Sirtori, E. Bosisio, V. Gualandri, G. B. Orsini, A. M. Mogavero, and A. Capurso. 1985. Relationship of the phenotypic expression of the A-I Milano apoprotein with plasma lipids and lipoprotein patterns. Atherosclerosis. 58:159-174.

18. Weisgraber, K. H., T. P. Bersot, R. W. Mahley, G. Franceschini, and C. R. Sirtori. 1980. Isolation and characterization of a cysteine containing variant of the A-I apoprotein from human density lipoproteins. J. Clin. Invest. 66:901-907.

19. Franceschini, G., M. Sirtori, C. Gianfranceschi, and C. R. Sirtori. 1981.

Relation between the HDL apoproteins and A-I isoproteins in subjects with the A-I Milano abnormality. Metabolism. 30:502-509.

20. Havel, R. J., H. A. Eder, and J. H. Bragdon. 1955. The distribution and chemical composition of ultracentrifugally separated lipoproteins in human serum. J. Clin. Invest. 34:1345-1353.

21. Lowry, O. H., N. J. Rosebrough, A. L. Farr, and R. J. Randall. 1951. Protein measurement with the Folin phenol reagent. J. Biol. Chem. 193:265275.

22. Brewer, H. B., Jr., R. Ronan, M. Meng, and C. Bishop. 1986. Isolation and characterization of apolipoproteins A-I, A-II, and A-IV. Methods Enzymol. 128:223-246.

23. Weber, K., and M. Osborn. 1969. The reliability of molecular weight determination by dodecyl sulfate polyacrylamide gel electrophoresis. $J$. Biol. Chem. 244:4406-4412.

24. Berman, M., and M. Weiss. 1978. SAAM Manual. Department of Health, Education and Welfare Publ. No. 78:180. National Institutes of Health, Bethesda, MD. 
25. Warnick, G. R., J. Benderson, J. J. Albers, E. E. Baillie, B. Sexton, E. J. Scheafer, D. Carlson, M. Hill, H. B. Brewer, Jr., D. A. Wiebe, et al. 1982. Dextran sulfate-magnesium precipitation procedure for quantitation of high density lipoprotein cholesterol. Clin. Chem. 28:1379-1388.

26. Schaefer, E. J., L. A. Zech, L. L. Jenkins, T. J. Bronzert, E. A. Rubacalba, R. L. Aamodt, and H. B. Brewer, Jr. 1982. Human apolipoprotein A-I and A-II metabolism. J. Lipid Res. 23:850-862.

27. Sprecher, D. L., L. Taam, and H. B. Brewer, Jr. 1984. Two dimensional electrophoresis of human plasma apolipoproteins. Clin. Chem. 30:2084-2092.

28. Franceschini, G., G. Vecchio, G. Gianfranceschi, D. Magani, and C. R. Sirtori. 1985. Apolipoprotein A-I Milano. Accelerated binding and dissociation from lipids of a human apolipoprotein variant. J. Biol. Chem. 260:16321-16325.

29. Franceschini, G., T. G. Frosi, C. Manzoni, G. Gianfranceschi, and C. R.
Sirtori. 1982. High density lipoprotein ${ }_{3}$ heterogeneity in subjects with the apo A-I Milano variant. J. Biol. Chem. 257:9926-9930.

30. Cheung, M. C., A. V. Nichols, P. J. Blanche, E. L. Gong, G. Franceschini, and C. R. Sirtori. 1988. Characterization of A-I containing lipoproteins in subjects with A-I Milano variant. Biochim. Biophys. Acta. 960:73-82.

31. Franceschini, G., L. Calabresi, C. Tosi, G. Gianfranceschi, C. R. Sirtori, and A. V. Nichols. 1990. Apolipoprotein A-I Milano: disulfide-linked dimers increase high density lipoprotein stability and hinder particle interconversion in carrier plasma. J. Biol. Chem. 265:12224-12231.

32. Franceschini, G., M. Baio, L. Calabresi, C. R. Sirtori, and M. C. Cheung. 1990. Apolipaprotein A-I $I_{\text {Miluno }}$. Partial lecithin:cholesterol acyltransferase deficiency due to low levels of a functional enzyme. Biochim. Biophys. Acta. 1043:1-6. 